\title{
Influence of Ivabradine on the Anticonvulsant Action of Four Classical Antiepileptic Drugs Against Maximal Electroshock- Induced Seizures in Mice
}

\author{
Katarzyna M. Sawicka ${ }^{1} \cdot$ Agnieszka Wawryniuk $^{1} \cdot$ Agnieszka Zwolak $^{1}$. \\ Jadwiga Daniluk $^{1} \cdot$ Monika Szpringer $^{2} \cdot$ Magdalena Florek-Luszczki $^{3}$ • \\ Bartlomiej Drop $^{1} \cdot$ Dorota Zolkowska $^{4} \cdot$ Jarogniew J. Luszczki $^{1}$
}

Received: 26 August 2016 / Revised: 28 October 2016 / Accepted: 3 December 2016 / Published online: 12 January 2017

(C) The Author(s) 2017. This article is published with open access at Springerlink.com

\begin{abstract}
Although the role of hyperpolarization-activated cyclic nucleotide-gated $(\mathrm{HCN})$ channels in neuronal excitability and synaptic transmission is still unclear, it is postulated that the HCN channels may be involved in seizure activity. The aim of this study was to assess the effects of ivabradine (an HCN channel inhibitor) on the protective action of four classical antiepileptic drugs (carbamazepine, phenobarbital, phenytoin and valproate) against maximal electroshock-induced seizures in mice. Tonic seizures (maximal electroconvulsions) were evoked in adult male albino Swiss mice by an electric current (sine-wave, $25 \mathrm{~mA}, 0.2 \mathrm{~s}$ stimulus duration) delivered via auricular electrodes. Acute adverse-effect profiles of the combinations of ivabradine with classical antiepileptic drugs were measured in mice along with total brain antiepileptic drug concentrations. Results indicate that ivabradine $(10 \mathrm{mg} /$ $\mathrm{kg}$, i.p.) significantly enhanced the anticonvulsant activity of valproate and considerably reduced that of phenytoin in the mouse maximal electroshock-induced seizure model. Ivabradine $(10 \mathrm{mg} / \mathrm{kg})$ had no impact on the anticonvulsant potency of carbamazepine and phenobarbital in the maximal electroshock-induced seizure test in mice. Ivabradine $(10 \mathrm{mg} / \mathrm{kg})$ significantly diminished total brain concentration of phenytoin and had no effect on total brain valproate concentration in mice. In conclusion, the enhanced anticonvulsant action of valproate by ivabradine in the mouse
\end{abstract}

Jarogniew J. Luszczki

jluszczki@yahoo.com

Medical University in Lublin, Lublin, Poland

2 The Jan Kochanowski University in Kielce, Kielce, Poland

3 Institute of Rural Health, Lublin, Poland

4 School of Medicine, University of California-Davis, Sacramento, California, USA maximal electroshock-induced seizure model was pharmacodynamic in nature. A special attention is required when combining ivabradine with phenytoin due to a pharmacokinetic interaction and reduction of the anticonvulsant action of phenytoin in mice. The combinations of ivabradine with carbamazepine and phenobarbital were neutral from a preclinical viewpoint.

Keywords Antiepileptic drugs $\cdot$ Ivabradine $\cdot$ Maximal electroshock-induced seizures · Pharmacokinetic/ pharmacodynamic interaction

\section{Introduction}

Ivabradine, as a hyperpolarization-activated cyclic nucleotide-gated (HCN) channel blocker inhibits directly and selectively a depolarizing mixed sodium and potassium inward current, called the "funny" current $\left(\mathrm{I}_{f} / \mathrm{I}_{h}\right)$ in both, sino-atrial node and neurons [1-4]. Under physiological conditions, any increase or decrease in intracellular cyclic adenosine monophosphate (cAMP) level regulates the $\mathrm{I}_{\mathrm{f}} / \mathrm{I}_{\mathrm{h}}$ current, producing a shift in the voltage-dependent activation of the $I_{f} / I_{h}$ current [5]. Although the physiological role of the $I_{h}$ current in neurons is still unclear, the $I_{h}$ current is expected to play a pivotal role in seizure activity.

Experimental evidence indicates that ivabradine possesses the anticonvulsant properties by elevating, in a dose dependent manner, the threshold for electroconvulsions in mice and the experimentally determined $\mathrm{TID}_{20}$ and $\mathrm{TID}_{50}$ values (i.e., threshold increasing doses by 20 and 50\%) for ivabradine were 8.70 and $18.29 \mathrm{mg} / \mathrm{kg}$, respectively [6]. Since ivabradine, as an HCN channel blocker, elevates the threshold for electroconvulsions in mice, it can be expected that the drug will also be able to enhance the anticonvulsant 
potency of some classical antiepileptic drugs. Thus, a favorable effect observed for ivabradine in combination with classical antiepileptic drugs in experimental animals could significantly increase our knowledge about neuronal mechanisms involved in seizure initiation, propagation and amplification in the brain, especially, in these brain regions where $\mathrm{I}_{\mathrm{h}}$ currents are abundantly distributed in neurons.

The aim of this study was to assess the influence of ivabradine on the protective action of four classical antiepileptic drugs (carbamazepine, phenytoin, phenobarbital and valproate) in the mouse maximal electroshock-induced tonic seizure model. Generally, in the maximal electroshock seizure test it is possible to determine whether ivabradine was able to enhance or alleviate the anticonvulsant potency of the classical antiepileptic drugs in this seizure model, which is considered to be an experimental model of tonicclonic seizures and partial convulsions with or without secondary generalization in humans [7]. Additionally, the effects of ivabradine alone and in combination with the classical antiepileptic drugs were examined in three behavioral (chimney, passive avoidance, and grip-strength) tests to detect any possible impairment of motor coordination, disturbances in long-term memory, and changes in skeletal muscular strength in animals. To exclude any pharmacokinetic interactions for the observed effects in the mouse maximal electroshock-induced seizure model between ivabradine and the classical antiepileptic drugs, total brain antiepileptic drug concentrations were measured with fluorescence polarization immunoassay.

\section{Materials and Methods}

\section{Animals}

Adult male Albino Swiss mice (weighing 22-26 g), after 7 days of adaptation to laboratory conditions, were randomly assigned to experimental groups, each comprised 8 mice. All procedures involving animals and their care, described in this study, were approved by the First Local Ethics Committee for Animal Experiments at the Medical University of Lublin (License No.: 13/2015), and complied with the European Communities Council Directive of 24 November 1986 (86/609/EEC). All experiments on animals described below are in accordance with ARRIVE guidelines. Total number of animals used in this study was 320 .

\section{Drugs}

Ivabradine (Procoralan $®$, Les Laboratoires Servier, Neuilly-sur-Seine, France), carbamazepine (Polpharma, Starogard Gdański, Poland), phenobarbital (Polfa, Kraków, Poland), phenytoin (Polfa, Warszawa, Poland) were suspended in a $1 \%$ solution of Tween 80 (SigmaAldrich) in distilled water. Only valproate (sodium saltSigma-Aldrich) was directly dissolved in distilled water. All drugs were administered intraperitoneally (ip) as follows: phenytoin-120 min, ivabradine and phenobarbital-60 min, carbamazepine and valproate-30 min before maximal electroshock-induced seizures, behavioral (passive-avoidance, grip-strength and chimney) tests and before collection of brains for the measurement of antiepileptic drug concentrations, as documented earlier $[6,8-10]$.

\section{Maximal Electroshock Seizure Test}

In the maximal electroshock seizure test, mice were challenged with a current (sine-wave, $25 \mathrm{~mA}, 50 \mathrm{~Hz}, 500 \mathrm{~V}$, stimulus duration $0.2 \mathrm{~s}$ ) delivered via ear-clip electrodes from a rodent shocker generator (Hugo Sachs Elektronik, Freiburg, Germany). The tonic hind limb extension in mice was the endpoint. The classical antiepileptic drugs administered singly and their combination with ivabradine were tested for their ability to increase the number of mice protected from maximal electroconvulsions. Logprobit method [11] was used to determine median effective dose $\left(\mathrm{ED}_{50}\right)$ values for the antiepileptic drugs tested. The mice were injected with ivabradine in doses of 5 and $10 \mathrm{mg} / \mathrm{kg}$ that by themselves did not significantly affect the threshold for electroconvulsions [6]. Total number of animals used in this procedure was 240 .

\section{Measurement of Total Brain Antiepileptic Drug Concentrations}

The measurement of total brain concentrations of phenytoin and valproate (at doses that corresponded to their $\mathrm{ED}_{50}$ values from the maximal electroshock seizure test) was performed by a fluorescence polarization immunoassay. The mice received a given antiepileptic drug alone and in combination with ivabradine $(10 \mathrm{mg} / \mathrm{kg})$, and subsequently, the mice were decapitated. The whole brains of mice were removed from the skulls, weighed, harvested and homogenized using Abbott buffer (1:2, w/v; Abbott Laboratories, North Chicago, IL, USA). The homogenates were centrifuged at $10,000 \times g$ for $10 \mathrm{~min}$ and the supernatant samples of $100 \mu \mathrm{l}$ were collected and then analyzed for phenytoin or valproate content by Abbott TDx analyzer, as described earlier [12]. Total brain phenytoin and valproate concentrations are expressed in $\mu \mathrm{g} / \mathrm{g}$ of wet brain tissue as the means \pm S.E.M. $(n=8$ mice per group). Total number of animals used in this procedure was 32. 


\section{Step-Through Passive Avoidance Task}

The assessment of any acute adverse effect potential of ivabradine $(10 \mathrm{mg} / \mathrm{kg})$ alone and in combination with classical antiepileptic drugs (at doses that corresponded to their $\mathrm{ED}_{50}$ values from the maximal electroshock seizure test) with respect to deficits in long-term memory in mice was quantified by the step-through passive avoidance task, as described earlier $[8,9,13]$. Long-term memory in mice is expressed as the median latencies (retention times) with 25th and 75th percentiles ( $n=8$ mice per group). Total number of animals used in this procedure was 48 .

\section{Grip-Strength Test}

The assessment of any acute adverse effect potential of ivabradine $(10 \mathrm{mg} / \mathrm{kg})$ alone and in combination with classical antiepileptic drugs (at doses that corresponded to their $\mathrm{ED}_{50}$ values from the maximal electroshock seizure test) with respect to changes in skeletal muscular strength in mice was quantified by the grip-strength test, as published elsewhere $[8,9,14]$. The skeletal muscular strength in mice is expressed in newtons $(\mathrm{N})$ as the means \pm S.E.M. $(n=8$ mice per group). Total number of animals used in this procedure was 48 .

\section{Chimney Test}

The assessment of any acute adverse effect potential of ivabradine $(10 \mathrm{mg} / \mathrm{kg})$ alone and in combination with classical antiepileptic drugs (at doses that corresponded to their $\mathrm{ED}_{50}$ values from the maximal electroshock seizure test) with respect to impairment of motor coordination in mice was performed by the use of the chimney test, as described earlier $[8,9,15]$. Results from the chimney test are expressed as percentage (\%) of animals showing motor coordination impairment $(\mathrm{n}=8$ mice per group). Total number of animals used in this procedure was 48 .

\section{Statistics}

Statistical analysis of data from the maximal electroshock seizure test was performed either with the log-probit method [11] for single comparisons between two $\mathrm{ED}_{50}$ values, or with one-way ANOVA, followed by the post-hoc Tukey-Kramer test for multiple comparisons among three $\mathrm{ED}_{50}$ values, as described earlier [16]. The unpaired Student's $t$ test was used to statistically compare total brain antiepileptic drug concentrations. The Fisher's exact probability test was used to analyze qualitative variables from the chimney test. The Kruskal-Wallis nonparametric ANOVA analyzed data from the passive avoidance task, whereas the results from the grip-strength test were statistically verified with one-way ANOVA. Statistical significance was established at $\mathrm{P}<0.05$.

\section{Results}

Influence of Ivabradine on the Protective Activity of Carbamazepine, Phenobarbital, Phenytoin and Valproate in the Mouse Maximal Electroshock Seizure Model

Ivabradine $(10 \mathrm{mg} / \mathrm{kg}$, i.p. ) significantly reduced the anticonvulsant potency of phenytoin by increasing its $\mathrm{ED}_{50}$ value from $12.80 \pm 0.94$ to $17.99 \pm 1.07 \mathrm{mg} / \mathrm{kg}(\mathrm{P}<0.01)$ $(\mathrm{F}(2 ; 61)=5.993 ; \mathrm{P}=0.004 ;$ Fig. 1c $)$. On the contrary, ivabradine $(10 \mathrm{mg} / \mathrm{kg}$, i.p.) considerably potentiated the anticonvulsant action of valproate by decreasing its $\mathrm{ED}_{50}$ value from $311.2 \pm 11.7$ to $248.2 \pm 18.3 \mathrm{mg} / \mathrm{kg}(\mathrm{P}<0.05)$ $(\mathrm{F}(2 ; 61)=3.456 ; \mathrm{P}=0.038$; Fig. 1d). Ivabradine $(5 \mathrm{mg} /$ $\mathrm{kg}$ ) had no significant impact on the anticonvulsant action of phenytoin and valproate in the mouse maximal electroshock seizure model (Fig. 1c, d). Similarly, ivabradine $(10 \mathrm{mg} / \mathrm{kg}$, ip) did not significantly alter the anticonvulsant action of carbamazepine or phenobarbital in the maximal electroshock seizure test in mice (Fig. 1a, b).

\section{Influence of Ivabradine on Total Brain Phenytoin and Valproate Concentrations}

As measured by fluorescent polarization immunoassay method, total brain concentrations of phenytoin $(18.0 \mathrm{mg} /$ $\mathrm{kg}$ ) administered separately were $2.12 \pm 0.24 \mu \mathrm{g} / \mathrm{g}$ of wet brain tissue, whereas those of phenytoin $(18.0 \mathrm{mg} /$ $\mathrm{kg})$ in combination with ivabradine $(10 \mathrm{mg} / \mathrm{kg})$ were significantly reduced, amounting to $1.29 \pm 0.27 \mu \mathrm{g} / \mathrm{g}$ of wet brain tissue $(\mathrm{P}<0.05)$. In contrast, ivabradine $(10 \mathrm{mg} / \mathrm{kg})$ had no significant impact on total brain concentration of valproate $(248.2 \mathrm{mg} / \mathrm{kg})$. In this case, the total brain concentrations of valproate $(248.2 \mathrm{mg} / \mathrm{kg})$ administered alone were $99.6 \pm 12.2 \mu \mathrm{g} / \mathrm{g}$ of wet brain tissue and did not differ significantly from those for the combination of valproate $(248.2 \mathrm{mg} / \mathrm{kg})$ with ivabradine $(10 \mathrm{mg} / \mathrm{kg})$, which were $105.3 \pm 11.5 \mu \mathrm{g} / \mathrm{g}$ of wet brain tissue.

\section{Effects of Ivabradine Alone and in Combination with Various Antiepileptic Drugs on Motor Performance, Long-Term Memory, and Skeletal Muscular Strength of Animals}

Ivabradine $(10 \mathrm{mg} / \mathrm{kg}$, i.p. $)$ administered alone and in combination with the studied four classical antiepileptic drugs did not disturb long-term memory, alter skeletal muscular strength or impair motor performance in mice, as 
Fig. 1 a-d Effect of ivabradine (IVAB) on the protective activity of carbamazepine (CBZ), phenobarbital (PB), phenytoin (PHT), and valproate (VPA) against maximal electroshockinduced seizures in mice. Left panel Dose-response function for the anticonvulsant (protective) activity of classical antiepileptic drugs [CBZ (a), PB (b), PHT (c) and VPA (d)] alone and in combination with ivabradine (IVAB) in the mouse maximal electroshock-induced seizure model. Each data point represents percent of mice protected $(\mathrm{n}=8 \mathrm{mice} / \mathrm{data}$ point $)$ from maximal electroshockinduced seizures at a given dose (in $\mathrm{mg} / \mathrm{kg}$ ). Sigmoidal curves are the result of a least squares fit of dose-response function for each antiepileptic drug. Points of intersections with the dashed line at $50 \%$ correspond to approximate $\mathrm{ED}_{50}$ values of antiepileptic drugs. Right panel Columns represent median effective doses $\left(\mathrm{ED}_{50}\right.$ in $\mathrm{mg} / \mathrm{kg} \pm$ S.E.M.) of antiepileptic drugs that protect $50 \%$ of animals tested against maximal electroshock-induced seizures in mice. The log-probit method was used for calculating the $\mathrm{ED}_{50}$ values and statistical analysis of data was performed either with log-probit method for single comparison $(\mathbf{a}, \mathbf{b})$ or with one-way ANOVA followed by the post-hoc Tukey-Kramer test for multiple comparisons (c, d). $* \mathrm{P}<0.05$ and $* * \mathrm{P}<0.01$ versus control (antiepileptic drug + vehicle-treated) animals
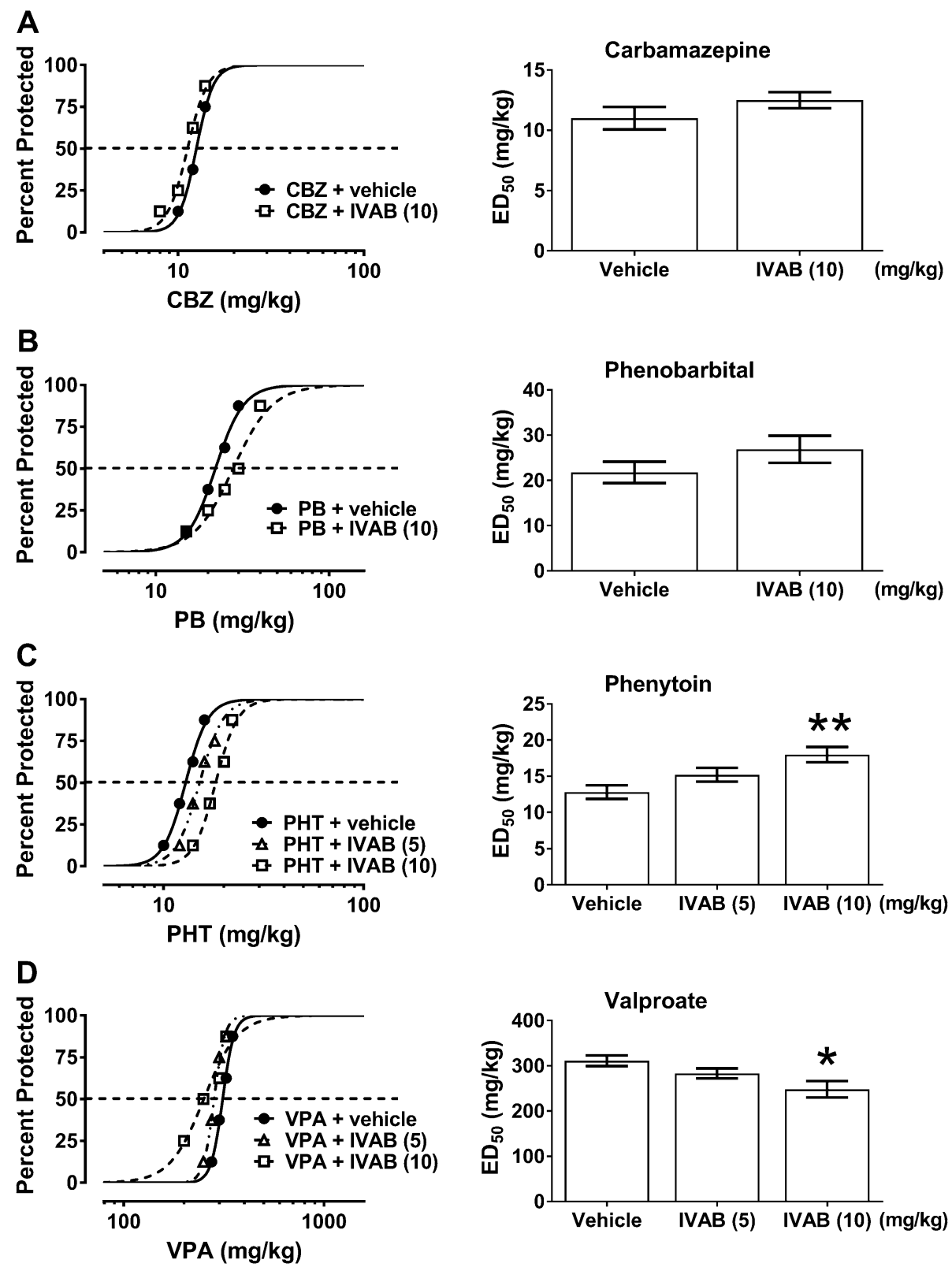

Table 1 Effects of ivabradine and its combination with four classical antiepileptic drugs on long-term memory in the passive avoidance task, motor performance in the chimney test and muscular strength in the grip-strength test in mice

\begin{tabular}{llll}
\hline Treatment $(\mathrm{mg} / \mathrm{kg})$ & Retention time $(\mathrm{s})$ & Muscular strength $(\mathrm{N})$ & $\begin{array}{l}\text { Motor coordina- } \\
\text { tion impairment } \\
(\%)\end{array}$ \\
\hline Vehicle & $180(180 ; 180)$ & $1.087 \pm 0.067$ & 0 \\
Ivabradine (10) + Vehicle & $180(180 ; 180)$ & $1.052 \pm 0.071$ & 12.5 \\
Carbamazepine (12.5) + Ivabradine (10) & $180(180 ; 180)$ & $1.049 \pm 0.065$ & 0 \\
Phenobarbital (26.9) + Ivabradine (10) & $180(180 ; 180)$ & $1.048 \pm 0.062$ & 0 \\
Phenytoin (18.0) + Ivabradine (10) & $180(180 ; 180)$ & $1.062 \pm 0.072$ & 0 \\
Valproate (248.2) + Ivabradine (10) & $177.5(155.5 ; 180)$ & $1.063 \pm 0.069$ & 12.5 \\
\hline
\end{tabular}

Results are presented as: median retention times [in seconds (s); with 25 th and 75th percentiles in parentheses] from the passive avoidance task; mean muscular strengths [in newtons $(\mathrm{N}) \pm$ S.E.M.] from the gripstrength test; and percentage (\%) of animals with impairment of motor coordination from the chimney test. Each experimental group consisted of 8 mice 
determined in the passive avoidance task, grip-strength test, and chimney test, respectively (Table 1).

\section{Discussion}

Results reported in this study indicate that ivabradine, as the inhibitor of $\mathrm{HCN}$ channels, enhanced the anticonvulsant potency of valproate against maximal electroshock-induced seizures in mice. Pharmacokinetic study revealed that the enhancement of the anticonvulsant potency of valproate (by $20 \%$ ) was associated with a non-significant (6\%) increase in total brain concentration of valproate in mice. Thus, it was confirmed that the observed potentiation of the anticonvulsant potency of valproate in this seizure model by ivabradine was pharmacodynamic in nature. To explain the observed potentiation of the antiseizure effects of valproate by ivabradine, one should consider molecular mechanisms of action of both drugs. Ivabradine is a drug that selectively and directly blocks the $\mathrm{I}_{\mathrm{f}} / \mathrm{I}_{\mathrm{h}}$ channels in neurons $[4,17]$. Valproate blocks low-threshold T-type calcium channels, enhances GABA-ergic neurotransmission in the brain and increases the potassium-induced release of GABA in neurons. Additionally, valproate increases synthesis of GABA by activating glutamic acid decarboxylase-a GABA synthesizing enzyme. Valproate activates potassium conductance and elevates GABA levels in specific brain regions by inhibiting GABA-transaminase-an enzyme catalyzing GABA degradation (for review see: $[18,19])$. Although it is difficult to comprehend the exact nature of the synergistic effect from their respective mechanisms of action, this study clearly indicates that ivabradine synergistically cooperates with valproate in terms of suppression of maximal electroshock-induced seizures.

In contrast, ivabradine did not significantly affect the anticonvulsant action of carbamazepine and phenobarbital in the mouse maximal electroshock seizure model, therefore, total brain concentrations of these antiepileptic drugs were not estimated in the presented study. On the other hand, pharmacokinetic experiments using fluorescence polarization immunoassay revealed that ivabradine considerably reduced (by 39\%) total brain concentrations of phenytoin in mice, confirming that a pharmacokinetic interaction between drugs was entirely responsible for the observed reduction (by $41 \%$ ) of the $\mathrm{ED}_{50}$ value of phenytoin in the maximal electroshock-induced seizure test in mice when combined with ivabradine. The explanation of this phenomenon may, at least in part, depend on the reduction of the heart rate in the mice exposed to the combination of phenytoin and ivabradine. Since phenytoin belongs to the subclass IB of antiarrhythmic drugs
[20], and ivabradine is a specific heart rate-lowering compound $[17,21]$, it is possible that the combination of these two drugs may significantly reduce the heart rate in laboratory mice. Thus, it can be observed a decrease in some pharmacokinetic parameters characterizing distribution of phenytoin in mice, including, its penetration through the blood-brain barrier and dispersion of phenytoin in the brain tissue. Although this suggestion is highly speculative, it can easily explain the observed pharmacokinetic reduction in total brain concentrations of phenytoin after co-administration of ivabradine.

Previously, it was documented that phenytoin (applied in a dose of $150 \mathrm{mg}$ twice daily) pharmacokinetically reduced (by approx. 70\%) bioavailability of ivabradine (applied in a single dose of $10 \mathrm{mg}$ ) in 18 healthy volunteers [22]. Since phenytoin is an inductor of the main metabolizing enzyme of ivabradine (CYP3A4), it is highly likely that the antiepileptic drug affects pharmacokinetics of ivabradine. Of note, ivabradine is metabolized only by CYP3A4 [23], whereas phenytoin mainly by CYP2C9 and CYP2C19 [24]. Thus, the mutual induction of CYP isoenzymes should be borne in mind while explaining the observed pharmacokinetic reduction in total brain phenytoin concentration in experimental animals receiving ivabradine. On the other hand, valproate is also metabolized by CYP2C9 [24], and ivabradine as an inducer of CYP2C9 should also reduce valproate concentrations in animals. Since no significant changes in valproate concentrations were observed in the mouse brain tissue, this pharmacokinetic mechanism was rather not responsible for the observed effects. To thoroughly characterize pharmacokinetic parameters for the interaction between ivabradine and phenytoin, more advanced pharmacokinetic studies, based on simultaneous estimation of distribution, metabolism and elimination of both drugs are required.

In this study, we also found that ivabradine combined with four classical antiepileptic drugs, at doses corresponding to their $\mathrm{ED}_{50}$ values from the maximal electroshock seizure test, did not affect acute adverse effects produced by classical antiepileptic drugs in the chimney, step-through passive avoidance and grip-strength tests in mice. Results from these behavioral tests may indirectly suggest that the heart rate-lowering effect of the combination of phenytoin with ivabradine was not so meaningful, permitting the animals to correctly perform all the studied behavioral tests without any significant impairment in locomotor activity, learning and skeletal muscular strength in mice. The similar situation was documented in animals receiving ivabradine in combination with carbamazepine, phenobarbital and valproate. 


\section{Conclusion}

The application of ivabradine together with valproate may be clinically favorable due to the pharmacodynamic enhancement of the anticonvulsant potency of the latter drug. In contrast, a special attention is advised to patients receiving phenytoin with ivabradine because of pharmacokinetic reduction of phenytoin concentrations that may result in alleviation of protection of the antiepileptic drug from seizures. In the case of the combinations of ivabradine with carbamazepine or phenobarbital, no significant changes in the anticonvulsant properties of the studied antiepileptic drugs are expected. If the results from this preclinical study could be translated to clinical settings, ivabradine would be combined with classical antiepileptic drugs, except for phenytoin.

Acknowledgements The funding was provided by Medical University in Lublin (Grant Number: DS 506/2015-2016).

Open Access This article is distributed under the terms of the Creative Commons Attribution 4.0 International License (http:// creativecommons.org/licenses/by/4.0/), which permits unrestricted use, distribution, and reproduction in any medium, provided you give appropriate credit to the original author(s) and the source, provide a link to the Creative Commons license, and indicate if changes were made.

\section{References}

1. DiFrancesco D, Camm JA (2004) Heart rate lowering by specific and selective I(f) current inhibition with ivabradine: a new therapeutic perspective in cardiovascular disease. Drugs 64:1757-1765

2. Bucchi A, Barbuti A, Difrancesco D, Baruscotti M (2012) Funny current and cardiac rhythm: insights from HCN knockout and transgenic mouse models. Front Physiol 3:240.

3. Bucchi A, Baruscotti M, Nardini M, Barbuti A, Micheloni S, Bolognesi M, DiFrancesco D (2013) Identification of the molecular site of ivabradine binding to HCN4 channels. PLoS ONE 8:e53132

4. Shah MM, Huang Z, Martinello K (2013) HCN and KV7 (M-) channels as targets for epilepsy treatment. Neuropharmacology 69:75-81

5. Manz M, Reuter M, Lauck G, Omran H, Jung W (2003) A single intravenous dose of ivabradine, a novel I(f) inhibitor, lowers heart rate but does not depress left ventricular function in patients with left ventricular dysfunction. Cardiology 100:149-155

6. Luszczki JJ, Prystupa A, Andres-Mach M, Marzeda E, FlorekLuszczki M (2013) Ivabradine (a hyperpolarization activated cyclic nucleotide-gated channel blocker) elevates the threshold for maximal electroshock-induced tonic seizures in mice. Pharmacol Rep 65:1407-1414

7. Loscher W, Fassbender CP, Nolting B (1991) The role of technical, biological and pharmacological factors in the laboratory evaluation of anticonvulsant drugs. II. Maximal electroshock seizure models. Epilepsy Res 8:79-94

8. Luszczki JJ, Czuczwar P, Cioczek-Czuczwar A, Czuczwar SJ (2006) Arachidonyl-2'-chloroethylamide, a highly selective cannabinoid CB1 receptor agonist, enhances the anticonvulsant action of valproate in the mouse maximal electroshock-induced seizure model. Eur J Pharmacol 547:65-74

9. Luszczki JJ, Czernecki R, Wojtal K, Borowicz KK, Czuczwar SJ (2008) Agmatine enhances the anticonvulsant action of phenobarbital and valproate in the mouse maximal electroshock seizure model. J Neural Transm (Vienna) 115:1485-1494

10. Kondrat-Wróbel MW, Łuszczki JJ (2016) Interaction of threedrug combination of lacosamide, carbamazepine and phenobarbital in the mouse maximal electroshock-induced seizure model - an isobolographic analysis. Health Probl Civil 10:55-61

11. Litchfield JT Jr, Wilcoxon F (1949) A simplified method of evaluating dose-effect experiments. J Pharmacol Exp Ther 96:99-113

12. Luszczki JJ, Ratnaraj N, Patsalos PN, Czuczwar SJ (2006) Isobolographic analysis of interactions between loreclezole and conventional antiepileptic drugs in the mouse maximal electroshock-induced seizure model. Naunyn Schmiedebergs Arch Pharmacol 373:169-181

13. Venault P, Chapouthier G, de Carvalho LP, Simiand J, Morre M, Dodd RH, Rossier J (1986) Benzodiazepine impairs and betacarboline enhances performance in learning and memory tasks. Nature 321:864-866

14. Meyer OA, Tilson HA, Byrd WC, Riley MT (1979) A method for the routine assessment of fore- and hindlimb grip strength of rats and mice. Neurobehav Toxicol 1:233-236

15. Boissier JR, Tardy J, Diverres JC (1960) Une nouvelle méthode simple pour explorer l'action «tranquillisante»: le test de la cheminée. Pharmacology 3:81-84

16. Zolkowska D, Andres-Mach M, Prisinzano TE, Baumann MH, Luszczki JJ (2015) Modafinil and its metabolites enhance the anticonvulsant action of classical antiepileptic drugs in the mouse maximal electroshock-induced seizure model. Psychopharmacology (Berl) 232:2463-2479

17. Kitai T, Tang WHW (2016) Pathophysiologic insights into heart rate reduction in heart failure: implications in the use of betablockers and ivabradine. Curr Treat Options Cardiovasc Med 18:1-15

18. Czapinski P, Blaszczyk B, Czuczwar SJ (2005) Mechanisms of action of antiepileptic drugs. Curr Top Med Chem 5:3-14

19. Loscher W (2002) Basic pharmacology of valproate: a review after 35 years of clinical use for the treatment of epilepsy. CNS Drugs 16:669-694

20. Rizzon P, Di Biase M, Favale S, Visani L (1987) Class 1B agents lidocaine, mexiletine, tocainide, phenytoin. Eur Heart J 8(Suppl A):21-25

21. Kitai T, Tang WW (2015) Recent advances in treatment of heart failure. F1000Research. doi: 10.12688/f1000research.7022.1

22. Vlase L, Popa A, Neag M, Muntean D, Leucuta SE (2012) Pharmacokinetic interaction between ivabradine and phenytoin in healthy subjects. Clin Drug Investig 32:533-538

23. Portoles A, Calvo A, Terleira A, Laredo L, Resplandy G, Gorostiaga C, Moreno A (2006) Lack of pharmacokinetic interaction between omeprazole or lansoprazole and ivabradine in healthy volunteers: an open-label, randomized, crossover, pharmacokinetic interaction clinical trial. J Clin Pharmacol 46:1195-1203

24. Patsalos PN, Berry DJ, Bourgeois BF, Cloyd JC, Glauser TA, Johannessen SI, Leppik IE, Tomson T, Perucca E (2008) Antiepileptic drugs-best practice guidelines for therapeutic drug monitoring: a position paper by the subcommission on therapeutic drug monitoring, ILAE Commission on Therapeutic Strategies. Epilepsia 49:1239-1276 